\title{
Study of Elaeagnus angustifolia Fruit Aqueous Extract on the Histomorphometrical Changes of Retina in Mouse Embryo
}

\author{
Jamshid Arum, ${ }^{1}$ Mahnaz Azarnia, ${ }^{1}$ Gholamreza Kaka, ${ }^{2,}$ Seyed Hoomayoon Sadraei, ${ }^{2,3}$ and Mohammad \\ Kamalinejad $^{4}$ \\ ${ }^{1}$ Department of Animal Biology, Faculty of Biological Sciences, Kharazmi University, Tehran, IR Iran \\ ${ }^{2}$ Neuroscience Research Center, Baqiyatallah University of Medical Sciences, Tehran, IR Iran \\ ${ }^{3}$ Department of Anatomy, School of Medicine, Baqiyatallah University of Medical Sciences, Tehran, IR Iran \\ ${ }^{4}$ Department of Pharmacology, School of Medicine, Shahid Beheshti University of Medical Science, Tehran, IR Iran \\ "Corresponding author: Gholamreza Kaka, Neuroscience Research Center, Baqiyatallah University of Medical Sciences, Tehran, IR Iran. Tel/Fax: +98-2126127286, E-mail: \\ gh_kaka@yahoo.com
}

Received 2015 August 16; Revised 2015 October 19; Accepted 2016 September 24.

\begin{abstract}
Background: Modern societies tend to use herbs or traditional medicine because of fewer side effects than synthetic drugs. Elaeagnus angustifolia is a plant with many therapeutic effects.

Objectives: This study aimed to investigate the effect of aqueous extract of Elaeagnus angustifolia on fetal mice retina in Balb/C by evaluating of histomophometrical and immunohistochemical parameters in the eye mouse embryos

Methods: In this experimental study, thirty pregnant mice were randomly divided into two groups. Control group received food and drinking water, and the experimental group received food and the aqueous extract at a dose of $500 \mathrm{mg} / \mathrm{kg}$ in the form of water solution from the day zero of pregnancy up to the 18th day. Pregnant mice were killed and their fetuses were taken, fixed and stained with hematoxylin-eosin. Histomorphometrical and immunohistochemical changes of retin examined.

Results: The mean of Crown-Rump length and weight of fetuses significantly increased in experimental group compared to control group. In experimental group, a significant decrease was shown in the mean of diameters and weight of placenta compared to control group. Retinal thickness in posterior, superior and inferior part significantly reduced in experimental group compared to control group. however, retinal thickness in anterior part in experimental group was not different when compared to control group. The number of Ki-67-positive cells showed that the retinal cells proliferation in experimental group decreased compared to control group.

Conclusions: The use of aqueous extract of Elaeagnus angustifolia at dose of $500 \mathrm{mg} / \mathrm{kg}$ to pregnant mice caused the growth and histological changes on fetal mouse and in the retinal mouse development.
\end{abstract}

Keywords: Fetus, Mouse, Retina, Immunohistochemistry

\section{Background}

The use of medicinal plants is rapidly increasing in today's society [1]. In United States between 1990 and 1997 found that about $38 \%$ of the population was used medicinal plants [2] and it was found that medicinal plants consumers are mostly women [3]. Women during pregnancy may use these herbs as natural and safe substances [4]. Over the past few decades, researchers have focused on drug discovery from herbal medicines or botanical sources, an important group of complementary and alternative medicine therapy. With a long history of herbal usage for the clinical management of a variety of diseases in indigenous cultures, the success rate of developing a new drug from herbal medicinal preparations should, in the- ory, be higher than that from chemical synthesis [5]. When taking herbs during pregnancy their unwanted side effects and teratogenicity should be considerered [6]. Elaeagnus angustifolia contains considerable quantities of flavonoid, terpenoids, Sytoastrol, carvacrol, alkaloidsand vitamins such as A, B, C and metals such as copper, zinc, iron, etc. [7, 8]. Medicinal properties of Elaeagnus angustifolia can refer to its antinociceptive, anti-inflammatory, antibacterial and antioxidant effects $[9,10]$. Research has shown that Elaeagnus angustifolia compounds can easily cross the placental barrier and reach the fetus [11]. Talaei-Khozani et al. showed the effects of extracts of angustifolia on bone and cartilage in embryo mice limb bud in laboratory conditions and inside the body. In their experiments, pregnant mice were given $0.5,5.0$ or $50.0 \mathrm{mg} / \mathrm{kg}$ of the extract between days 
8 and 18 of gestation. They showed the higher concentrations of angustifolia extracts had no effect on chondrogenesis or osteogenesis. However, pregnant mice received 50 $\mathrm{mg} / \mathrm{kg}$ of this extract revealed a significant increase in their fetal femur and ossified zone length [12]. Since Elaeagnus angustifoliais possible to be used during pregnancy, it may has adverse effects on development of sensitive organ such as vision organ [13]. The aim of this study was to evaluate the effects of Elaeagnus angustifolia fruit aqueous extract on the histomorphometrical changes of retina in mouse embryo.

\section{Objectives}

Since, pregnant patients with joint pain and rheumatoid arthritis may used herbal extracts such Elaeagnus angustifolia. This study aimed to investigate the effect of aqueous extract of Elaeagnus angustifolia on fetal mice retina in Balb/C. In addition, this research consider to possible embryo toxic effects of prenatal exposure to Elaeagnus angustifolia by evaluating the histomophometrical and immunohistochemical parameters on the eye fetuses in the mouse embryos.

\section{Methods}

\subsection{Preparation of Aqueous Extract}

In this experimental study, all fruits were milled. Two hundred and fifty grams of milled fruit or its components were added to1000 $\mathrm{mL}$ water and boiled for 20 minutes, then filtered by a two-layer of fine mesh. The watery extract was concentrated on a boiling bath to the desired level, cooled and stored in a freezer at $-20^{\circ} \mathrm{C}$. The extract dissolved in distilled water to obtain a desired concentration before usage. To obtain moisture extract, two gram of final extract was placed in an oven in $60^{\circ} \mathrm{C}$ for 72 hours, and was then weighed and the weight loss was used as a moisture indicator. Thus, the final extract has $25 \%$ water.

\subsection{Animals}

After obtaining the approval of the institutional review board of our medical school, all experiments were carried out in accordance with the guidelines of the animal care and use ethics committee of Baqiyatallah University of medical sciences. Thirty adult Balb/C female mice weighting $33 \pm 7 \mathrm{~g}$, were maintained under standard laboratory conditions. Animals were housed in an environment of $21 \pm 0.5^{\circ} \mathrm{C}$ with a relative humidity of $50 \pm 10 \%$ and a 12 hours light-dark cycle. Food and water were always available. Estrous females were housed with Balb/C males for approximately 16 hours. The day of mating was considered day 0 of pregnancy. The pregnant mice were separated and were then randomly divided into experimental and control groups. Controls received tap water and aqueous extracts of Elaeagnus angustifolia at a dose of $500 \mathrm{mg} / \mathrm{kg}$ was administered orally (dissolved in drinking water) to the experimental groups from the first day to 18th day of pregnancy.

At 18th day of gestation, each pregnant mouse was killed from overdose of chloroform (Merk Co.). The uterine horns were exposed by laparotomy and their fetuses were removed from the uterus. In two groups fetuses were randomly selected from four to five litters. Fetal body weights and Crown-Rump lengths were measured and recorded. The fetuses were fixed in Bouin's fluid overnight, followed by dehydration through graded ethanol solutions and were then embedded and their heads were sagittaly sectioned at 5 micrometer thickness through the midsagital plane. For each embryo, 20 sections are randomly selected at predetermined uniform intervals from all sections cut of the region of interest, using this manner for histomorphometric studies. Then the sections were stained with $\mathrm{H}$ and $\mathrm{E}$ (hematoxylin-eosin) technique.

\subsection{Histomorphometric Studies}

The thickness of the four areas of retinal layers was directly measured by using a Motic hardware and software system with a microscopic magnification of $40 \mathrm{X}$ objective lens. For each section, three measurements were taken randomly from non-adjacent points of the different thickness of retinal layers from the upper, lower, posterior and anterior parts of retina using the computer-assisted morphometric software (Motic software).

\subsection{Cell Proliferation Assessment}

The standard method for assessment of cell proliferation in paraffin-embedded tissue sections is immunohistochemical analysis with the monoclonal antibody Ki67 , which reacts with a nuclear antigen in proliferating cells and then used avidin-biotin secondry antibody and stained with DAB chromogen.

The sections used for immunohistochemistry were dried at $37^{\circ} \mathrm{C}$ overnight, deparaffinized in xylene, and rehydrated through a series of graded ethyl alcohols. Endogenous peroxidase was inactivated by treatment with $3 \%$ $\mathrm{H}_{2} \mathrm{O}_{2}$ in $100 \%$ methanol for 5 minutes. Following a 5 minutes wash in phosphate-buffered saline (PBS, pH 7.4), microwave heat-induced antigen retrieval in $10 \mathrm{mmol} / \mathrm{l} \mathrm{cit}$ rate buffers, $\mathrm{pH}$ 6.0, was carried out. Non-specific staining was blocked by incubating the sections in 10\% normal horse serum for 1 hour at room temperature. Afterwards, the sections were incubated with the Ki-67 primary 
antibody at room temperature for overnight in $2 \%$ normal horse serum in a humidified chamber. Sections were then washed in PBS and incubated overnight in either a donkey anti-mouse secondary antibody conjugated to biotin or a donkey anti-rabbit secondary antibody conjugated to biotin (both at 1: 1000 and Sigma USA) in 2\% normal horse serum. Next, sections were washed in PBS and incubated with extravidin peroxidase (1: 1500 , Sigma USA) in $2 \%$ normal horse serum for 4 hours. Sections were then incubated for 7 minutes with the chromogen DAB (diaminobenzidine) and glucose oxidase (both from Sigma, USA) for visualization of antibody binding. Finally, the sections were counterstained with hematoxylin and Cell proliferation as a percentage of ki-67 labeling cells in retina tissue in two groups were also evaluated.

\subsection{Statistical Analysis}

The Kolmogorov-Smirnov test was used to assess the normality of distribution of investigated parameters. All parameters in our study were distributed normally. All data were expressed as Mean $\pm S D$. Differences were tested by SPSS 22 software package (SPSS Inc., Chicago, IL) using two-tailed t-test. The values $\mathrm{P}<0.05$ were considered statistically significant.

\section{Results}

\subsection{Fetal Body Weights and Crown-Rump Lengths}

The Crown-Rump length of the fetuses in experimental group significantly increased when compared to control group. Likewise, the mean body weight of the fetuses significantly increased in experimental group when compared to control group $(\mathrm{P}<0.05)$.

The mean number of fetuses in experimental group decreased when compared to control group but the differences were not significant. The mean weight, diameter and thickness of placenta of the fetuses in experimental group significantly decreased compared to control group $(\mathrm{P}<0.05)$ (Table 1$)$.

\subsection{Histomorphometric Studies}

Histomorphometric evaluations showed that the mean of retinal thickness in superior, inferior and posterior parts significantly decreased in experimental group in comparison with the control group but the mean of retinal thickness in anterior part of experimental group has not any significance in comparison with control group (Figures 1 and 2).
Table 1. Effect of Elaeagnus angustifolia Fruit Aqueous Extract on Fetal Weight, CrownRump Length, Number of Fetuses, Weight and Diameter of Placenta ${ }^{a}$

\begin{tabular}{lcc}
\hline Parameters & Control & Experimental \\
\hline Fetal weight, $\mathbf{g}$ & $1.15 \pm 0.03$ & $1.38 \pm 1.35^{*}$ \\
\hline Crown-Rump length, $\mathbf{m m}$ & $19.96 \pm 2.78$ & $22.02 \pm 3.47^{*}$ \\
\hline Number of fetuses & $5.53 \pm 3.05$ & $4.69 \pm 2.64$ \\
\hline Weight of placenta, $\mathbf{g}$ & $0.18 \pm 0.05$ & $0.15 \pm 0.03^{*}$ \\
\hline Diameter of placenta, $\mathbf{m m}$ & $8.06 \pm 0.87$ & $7.62 \pm 0.53^{*}$ \\
\hline Thickness of placenta, $\mathbf{m m}$ & $2.78 \pm 0.51$ & $2.69 \pm 0.37^{*}$ \\
\hline
\end{tabular}

${ }^{\mathrm{a}}$ Significantly different from control group $(\mathrm{P}<0.05)$.

\subsection{Immunohistochemistry Results}

Our immunostaining finding showed the number of Ki-67-positive cells in experimental group was decreased when compared to control group (Figure 3).

\section{Discussion}

Our study showed a significant increase in the weight and Crown-Rump length of embryos in the experimental group compared to controls. In agreement with our results are the findings of Talaei-Khozani about the effects of Elaeagnus angustifolia extract on bone and cartilage formation in mouse limb bud who reported pregnant mice received $50 \mathrm{mg} / \mathrm{kg}$ of this extract revealed a significant increase in their fetal femur and ossified zone length [12]. The influence of Elaeagnus angustifolia extract in the increase Crown-Rump length pattern of embryos is probably due to Flavonoid as ingredients of the extract. In mammals, flavonoid was observed in the diet of mother's amniotic fluid, proving the placental transfer of this material as well as its anabolic effects on the embryos $[14,15]$. Flavonoids also caused the increase in calcium compounds in diaphyseal bone tissue in femoral culture systems in rats [16]. It seems that the increase of Crown-Rump length in the fetuses exposed to Elaeagnus angustifolia extract are due to follow increase of calcium compounds which in the presence of Flavonoid are absorbed in a higher measure.

On the other hand, our study showed a significant reduction in weight, diameter and thickness of the placenta in the experimental group compared to controls. Our experimental findings are in agreement with the results of Anvari et al. in 2011, who studied on the effects of Zataria multiflora Boiss and reported the consumption of Zataria multiflora Boiss in the second week of pregnancy, caused a significant decrease in the size of tail embryo and in the mean of placental diameter [17]. It seems that carvacrol is one of the common combinations of Elaeagnus angustifolia 
Figure 1. Photomicrographs of Fetal Retina and Lens, H and E Staining, Magnification 40X (A, B) and Magnification 100X (C, D, E, F, G, H, J and K).
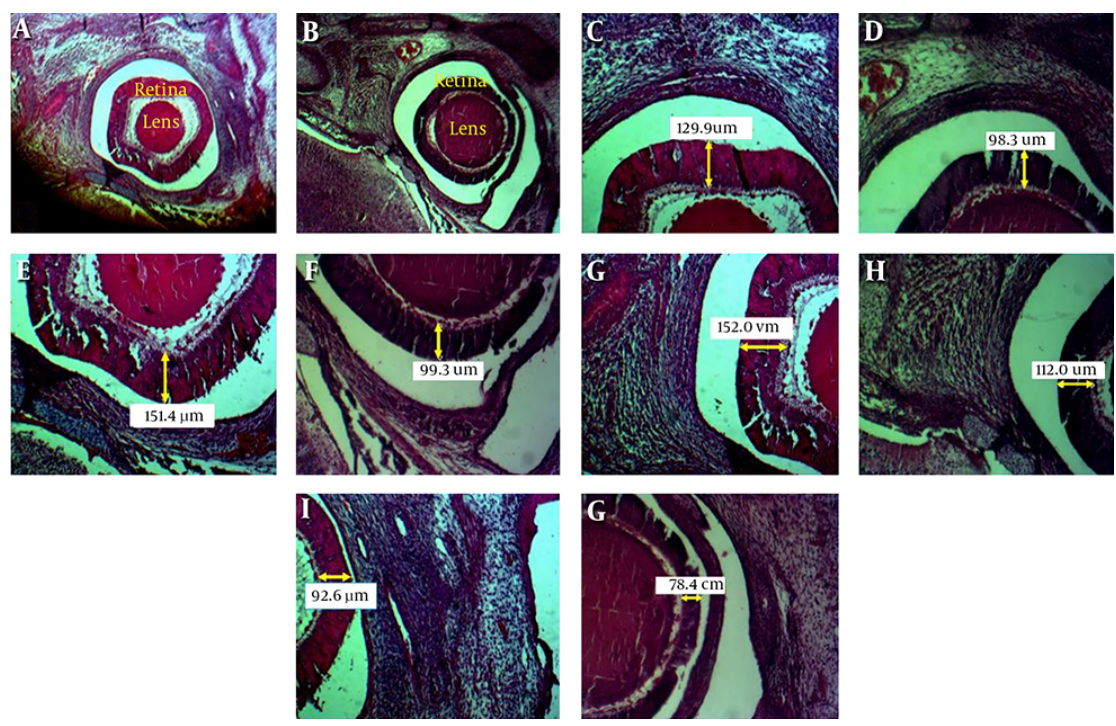

Photomicrographs in left column (A, C, E, G and J) are the control group and photomicrographs in right column (B, D, F, H and K) are the experimental group

A
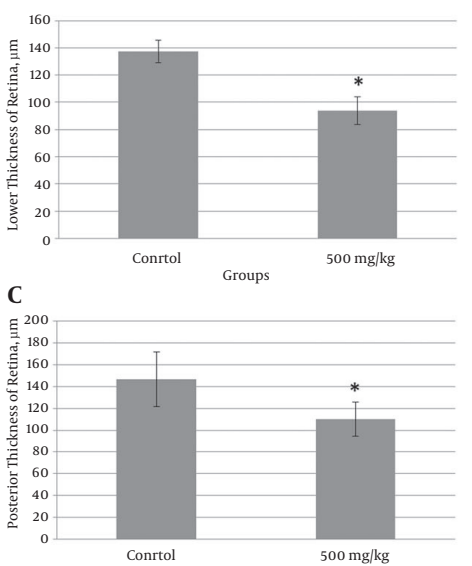

Groups
B
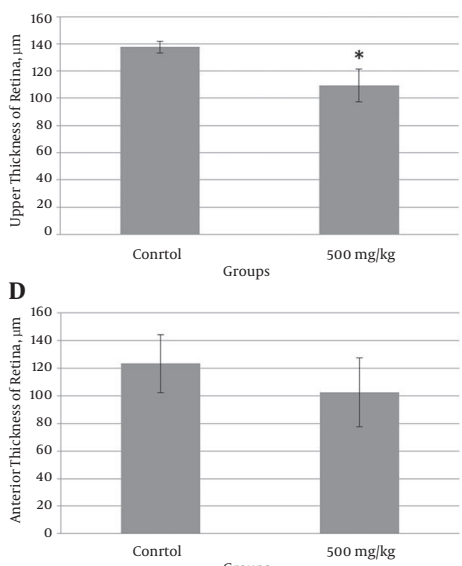

Figure 2. The retinal thickness of inferior part (A), superior part (B) and posterior part (C) significantly reduced in experimental group compared to control group. However, retinal thickness of anterior part (D) in the experimental group was not different when compared to control group.*Significantly different from control group $(\mathrm{P}<0.05)$.

and Zataria multiflora Boiss could produce these changes in the placenta in the experimental group $[18,19]$.

Our histomorphometrical results showed the decrease of retinal thickness in upper and lower parts in the experimental group compared to control group. It seems that presence of metals such as copper, zinc, etc. in Elaeagnus angustifolia extract may cause congenital malformations in the fetuses. Similarly, Parvari et al. revealed copper has a toxic effect on the central nervous system and can cause cellular changes in the embryonic nervous sys- tem and these changes could be seen in the forms of disorder in the cell positioning, increased intercellular spaces, cell swelling and nerve degeneration [20]. Similarly, teratogenic effects of Elaeagnus angustifolia extract has been shown on limb development [12]. It may be due to excessive amount of various vitamins A, C, E, and K. According to our finding, Rezaei et al. showed hyper vitamin $A$ is a potent teratogen that causes developmental abnormalities in the central nervous system [21]. Finally, our immunohistochemical results indicated ratinal hypocellularity in exper- 

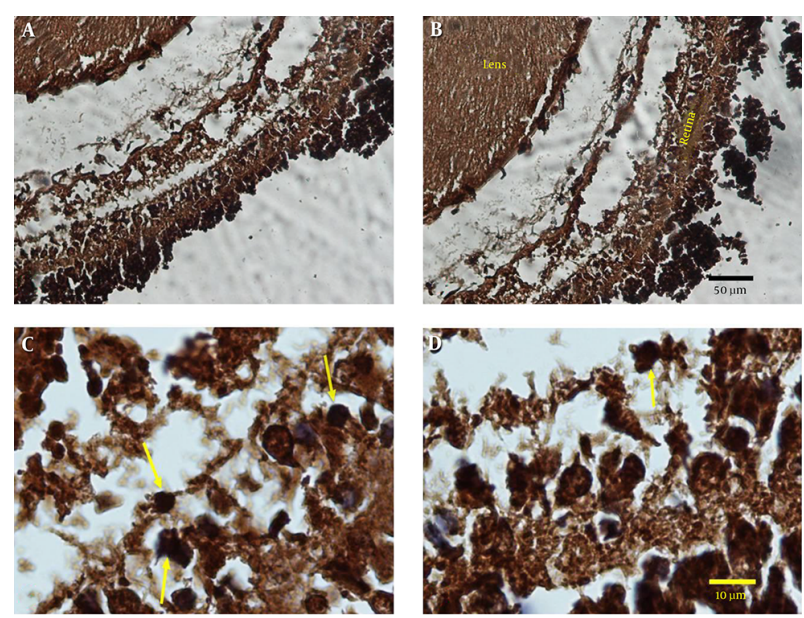

A, Control group (magnification $200 \times$ ); B, experimental group (magnification $200 \times$ ); C, control group (Magnification $1000 \times$ ); D, experimental group $($ Magnification 1000 $\times$ ). Yellow arrows showing Ki-67-positive cells.

imental group compared to control group. This results revealed that Elaeagnus angustifolia extract reduced cell proliferation in fetal mouse retina.

In conclusion, the data suggest that prenatal exposure to Elaeagnus angustifolia extract has toxic effects on growth of retina of embryos as well as on the fetal and placental development.

\section{Acknowledgments}

We are thanks from neuroscience research center, Baqiyatallah University of Medical Sciences for financial support of this research.

\section{Footnotes}

Authors' Contribution: Jamshid Arum, animal care, surgery of the animals and study design; Mahnaz Azarnia, histopathologic study; Gholamreza Kaka, histomorphometric study and data analysis; Seyed Hoomayoon Sadraei, histologic preparation and writing; Mohammad Kamalinejad, preparation of extract.

Conflict of Interest: The authors have no conflicts of interest.

Funding/Support: None declared

\section{References}

1. Ernst $\mathrm{E}$, White A. The BBC survey of complementary medicine use in the UK. Complement Ther Med. 2000;8(1):32-6. [PubMed: 10812758].
2. Eisenberg DM, Davis RB, Ettner SL, Appel S, Wilkey S, Van Rompay M, et al. Trends in alternative medicine use in the United States, 19901997: results of a follow-up national survey. JAMA. 1998;280(18):156975. [PubMed: 9820257].

3. MacLennan AH, Wilson DH, Taylor AW. Prevalence and cost of alternative medicine in Australia. Lancet. 1996;347(9001):569-73. [PubMed: 8596318].

4. Chez RA, Jonas WB. Complementary and alternative medicine. Part II: Clinical studies in gynecology. Obstet Gynecol Surv. 1997;52(11):709-16. [PubMed: 9357045].

5. Pan SY, Zhou SF, Gao SH, Yu ZL, Zhang SF, Tang MK, et al. New Perspectives on How to Discover Drugs from Herbal Medicines: CAM's Outstanding Contribution to Modern Therapeutics. Evid Based Complement Alternat Med. 2013;2013:627375. doi: 10.1155/2013/627375. [PubMed: 23634172].

6. Shariatzadeh MS, Azarnia M, Kaka GH, Shogh N, Sadraie SH. Study of Teratogenic Effects of Extract of Berberis Integerrima on Liver Tissue in Mouse Embryo. $2013 ; \mathbf{4}(1): 63-70$.

7. Goncharova N, Glushenkova A, Khim P. Lipids of oleaster fruits. Soedin. 1990;1:17-21.

8. Kousova RD, Kazakov A. Phololic compounds in fruit of Elaeagnus angustifolia. Soedin. 1998;3:455-6.

9. Ramezani M, Hosseinzadeh H, Daneshmand N. Antinociceptive effect of Elaeagnus angustifolia fruit seeds in mice. Fitoterapia. 2001;72(3):255-62. [PubMed: 11295301].

10. Ahmadiani A, Hosseiny J, Semnanian S, Javan M, Saeedi F, Kamalinejad $\mathrm{M}$, et al. Antinociceptive and anti-inflammatory effects of Elaeagnus angustifolia fruit extract. J Ethnopharmacol. 2000;72(1-2):287-92. [PubMed: 10967484].

11. Degen GH, Janning P, Diel P, Michna H, Bolt HM. Transplacental transfer of the phytoestrogen daidzein in DA/Han rats. Arch Toxicol. 2002;76(1):23-9. doi: 10.1007/s00204-001-0305-7. [PubMed: 11875621].

12. Talaei-Khozani T, Vojdani Z, Dehghani F, Heidari E, Kharazinejad E, Panjehshahin MR. Toxic effects of Elaeagnus angustifolia fruit extract on chondrogenesis and osteogenesis in mouse limb buds. Tokai J Exp Clin Med. 2011;36(3):63-70. [PubMed: 21932186].

13. Najd F, Sadraie SH, Azarnia M, Kaka G, Kamalinejad M. A Survey on the Effects of Elaeagnus Angustifolia Extract on Liver Tissue of Mouse Embryo. J Sabzevar Univ Med Sci. 2015;21(6):985-92. 
14. Engel SM, Levy B, Liu Z, Kaplan D, Wolff MS. Xenobiotic phenols in early pregnancy amniotic fluid. Reprod Toxicol. 2006;21(1):110-2. doi: 10.1016/j.reprotox.2005.07.007. [PubMed: 16112541].

15. Foster WG, Chan S, Platt L, Hughes CJ. Detection of phytoestrogens in samples of second trimester human amniotic fluid. Toxicol Lett. 2002;129(3):199-205. [PubMed: 11888703].

16. Yamaguchi M, Hamamoto R, Uchiyama S, Ishiyama K. Effects of flavonoid on calcium content in femoral tissue culture and parathyroid hormone-stimulated osteoclastogenesis in bone marrow culture in vitro. Mol Cell Biochem. 2007;303(1-2):83-8. doi: 10.1007/s11010007-9458-x. [PubMed: 17541507].

17. Anvari M, Dashti M, Zeinali F, Hosseini-Bioki SM. The effect of thyme (zataria multiflora boiss.): Decoction on pregnancy in rats. Med
Plants. 2011;2(38):19-25.

18. Saleem M, Nazli R, Afza N, Sami A, Ali MS. Biological significance of essential oil of Zataria multiflora boiss. Nat Prod Res. 2004;18(6):4937. doi: $10.1080 / 14786410310001608064$. [PubMed: 15595607].

19. Ultee A, Kets EP, Smid EJ. Mechanisms of action of carvacrol on the food-borne pathogen Bacillus cereus. Appl Environ Microbiol. 1999;65(10):4606-10. [PubMed:10508096].

20. Parvari S, Mehdizadeh M, Parivar K, Nobakht M. Teratogenic Effect of $\mathrm{CuCl} 2$ on the development of neural tube in Balb/C mouse embryo with emphasis on cervical spine. J Iran Univ Med Sci. 2003;4:105-12.

21. Rezaei N, Khalilian AR, Moghaddam AE, Hashemi SMB. Teratogenic Effect of Excess Vitamin A on the limb development in mouse embryo. $2001: 16-24$. 